\title{
The Association Between Islamic Lifestyle and Addiction Potential Among Adolescents
}

\author{
Ardenoush Padarvand ${ }^{1}$, Seyed Mohammad Kalantarkousheh ${ }^{1}$, Younes Doostian ${ }^{2}$, Omid Massah $^{2 *}$, Hamid Reza Varmazyar ${ }^{3}$, Moslem Arian \\ 1. Department of Counseling, Faculty of Psychology and Educational Sciences, Allameh Tabataba'i University, Tehran, Iran. \\ 2. Substance Abuse and Dependence Research Center, University of Social Welfare and Rehabilitation Sciences, Tehran, Iran \\ 3. Translator and Researcher, National Medical Academy of Iran, Tehran, Iran. \\ 4. University of Social Welfare and Rehabilitation Sciences, Tehran, Iran.
}

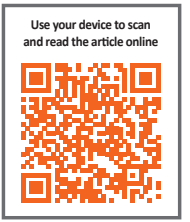

Citation: Padarvand, A., Kalantarkousheh, S. M., Doostian, Y., Massah, O., Varmazyar, H. R., Arian, M. (2017). The Association Between Islamic Lifestyle and Addiction Potential Among Adolescents. Journal of Practice in Clinical Psychology, 5(1), 27-32. https:// doi.org/10.18869/acadpub.jpcp.5.1.27

doi: : https://doi.org/10.18869/acadpub.jpcp.5.1.27

Article info:

Received: 21 Aug. 2016

Accepted: 11 Nov. 2016

Keywords:

Islamic lifestyle, Addiction potential, Adolescents

\section{ABSTRACT}

Objective: This study was conducted to investigate the association between Islamic lifestyle and addiction potential among adolescents residing in Eslamshahr City, Iran.

Methods: This was a cross sectional study. The statistical population consisted of all students attending public high schools during 2012-2013 academic year in Eslamshahr City. The sample size was 211, who were selected through multi-stage cluster sampling method. The Islamic lifestyle and addiction potential questionnaires were used to collect data.

Results: The Pearson correlation coefficient showed significant and inverse associations between the components of Islamic lifestyle and addiction potential, except for 'timeliness' $(\mathrm{P}<0.01)$.

Conclusion: Those adopting an Islamic lifestyle are less prone to substance abuse.

\section{Introduction}

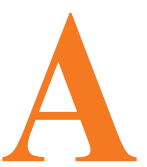

dolescence is often described as an important psychological period in one's life. No doubt, it is particularly an important period among the various stages of human life, as it has specific and unique characteristics. Adolescence is a period associated with special behavioral traits and even disorders and symptoms such as anxiety, depression, repeated bouts of anger, academic dysfunctioning, wearing weird clothes, casual cigarette smoking and use of other narcotics, iso- lation and running away from school. The consequences of these disorders and behaviors can later result in failure in academic achievement, unemployment, unsuccessful marital relations, unwanted pregnancy, addiction and so on (Cazenave \& Michel, 2008).

Adolescence is a period filled with severe turbulence and stress. It is likened to the time when the human race went through turbulent stages of urbanization (Hall, 1916). Moreover, adolescence has depicted as a critical period of turbulence, stress, and rebirth (Visser, Van der Ende, Koot, \& Verhulst, 2000). Studies have shown a worri-

* Corresponding Author:

Omid Massah, MD

Address: Substance Abuse and Dependence Research Center, University of Social Welfare and Rehabilitation Sciences, Koodakyar Alley, Daneshjoo Blv., Evin, Tehran, Iran.

Tel: +98 (21) 22180097

E-mail: omchomch@gmail.com 
some rise in psychological and emotional problems among students in recent years; abnormal phenomena such as suicide, addiction, academic failure, etc. have surfaced as new barriers and hindered students' progress (Farhoudian et al., 2006; Yousefi-Nooraie et al., 2009).

Addiction is one of the causes of physical and psychosocial disabilities that needs many rehabilitation services (Compton, Thomas, Stinson, \& Grant, 2007; Henderson Jr, 1991). Given the demographic structure of Iran and the spread of drug addiction among young people, more than half of our population are at risk. Drug abuse in many people begins since high-school age, so one of the most important strategies for reducing drug use is its control in adulthood (Bashirian, Heidarnia, \& Allahverdipour, 2013). Statistics show a rise in opiate abuse among adolescents and youth and a decline in the age of onset of drug abuse (Botvin, 2000; Narenjiha et al., 2009; Sarrami, Ghorbani, \& Minooei, 2013).

Different factors may be involved in addiction potential. According to research, the sensation seeking and absence or shortage of healthy recreational activities predispose adolescents and youngsters to addiction, which is very dangerous indeed (Massah, HoseinSabet, Doostian, A'zami, \& Farhoudian, 2014). It appears that many healthy or unhealthy habits adopted during a person's adolescent years tend to persist later in life and turn into a lifestyle. Lifestyle is defined as a person's overall framework for achievieng goals and overcoming difficulties in life. A person's specific way of life is labelled as 'lifestyle.' This concept has used through different interpretations such as self, character, individuality, shaping one's creative activities, and method of coping with problems (Dreikurs, 1991).

Kaviani believes that lifestyle examines an individual's behavior objectively, and goes beyond viewing congitions and emotions as mere mental constructs. However, Islamic lifestyle is different from the aforementioned. The Islamic lifestyle is concerned with behavior, feelings, emotions, and cognitions (Kaviani, 2011).

Research studies have been conducted on the association between lifestyle and individual disorders and traits. One study illustrated an association between teenage girls' self-esteem and lifestyle (Sahebzamani, Fesharaki, \& Abdollahi Mofrad, 2010). The results of studies conducted by Matud et al., Suzuki et al., and Suwazono et al. confirmed this relationship, too (Matud et al., 2004; Suwazono, Okubo, Kobayashi, Kido, \& Nogawa, 2003; Suzuki, Kitaike, Miyazaki, \& Nojiri, 2003).
Multiple studies have recognized the role of lifestyle in a person's potential for susbtance abuse (Pederson \& Stavraky, 1987; Zimmerman \& Maton, 1992). Another research performed by Baghiani-moghadam on addicts and nonaddicts showed a significant association between religiousness and addiction potential (Baghiani-Moghadam, Fazelpoor, \& Rahai, 2008).

Elsewhere, studies conducted by other researchers have also addressed the significance of religion as a protective factor against substance abuse among adolescents (Johnson, Sheets, \& Kristeller, 2008; Miri \& Bahrami, 2001; Piko \& Fitzpatrick, 2004).

Therefore, in light of the many physical, mental, social, familial and economic hazards of substance abuse, its significance during adolescence, and the dangers threatening this age group (who are our future generation), it seemed necessary to conduct this research and to find out any association between the Islamic lifestyle and addiction potential.

\section{Methods}

A cross sectional study was conducted in 2013 on highschool students. The statistical population consisted of all girls and boys attending Eslamshahr public high schools in 2012-2013 academic year. Based on sample size in similar correlational studies (Massah et al., 2014), the study sample comprised 260 subjects (130 girls and 130 boys), who were selected through random multistage cluster sampling method. After acquiring permission from Eslamshahr City Education Department, 6 public high schools were randomly selected ( 3 girl schools and 3 boy schools). Then, 3 classes were randomly selected from each school.

The questionnaires were administered after explaining the study's objectives, assuring confidentiality of data, and acquiring informed consent. Finally, information from 211 subjects (107 girls and 104 boys) were processed and analyzed. Inclusion criteria included being Muslim, enjoyment of physical and mental health, and consent to participate in the research. Physical and mental health of participants were examined and approved by a medical doctor who was expert in public health. Exclusion criteria included the presence of an addict in the family and nonhonest answers of samples to the questionnaire. The assessment tools applied were as follows:

Islamic lifestyle questionnaire: This questionnaire was developed by Kaviani and has two forms, the short and the long forms. It has 7 subscales (social, beliefs, ethical, familial, science \& contemplation, timeliness, and health) in the long form, the total number of questions is 
92. Each question has 4 response options, ranging from ' 1 ' (very little) to '4' (very much). The reliability and validity of the questionnaire have been evaluated on 300 subjects, where a Cronbach $\alpha$ of 0.78 was achieved (Kaviani, 2013). We estimated Cronbach $\alpha$ at 0.88 .

Addiction Potential Scale (APS): It was developed by Weed and Butcher in 1992. This questionnaire was standardized in Iran by Zargar (2006). It has 41 items (36 items and an additional 5 lie-detecting items). Each question has 4 response options, ranging from ' 0 ' (completely disagree) to ' 3 ' (completely agree). Two methods were used to assess the validity of this scale. Criterion validity evaluation showed that the scale differentiated very well between addicts and nonaddicts. The construct validity of the scale was calculated at 0.45 through correlating it with the symptom checklist (SCL-25), which was significant (Weed, Butcher, McKenna, \& Ben-Porath, 1992). The validity of the scale was calculated with Cronbach $\alpha$ and was estimated at 0.90, which was desirable (Zargar, Najarian, \& Naami, 2008). The internal consistency of the questionnaire in present study is 0.86 .

Ethical Considerations: In order to observe the ethical considerations, the study details were explained to participants who were assured of their information confidentiality. We used descriptive and inferential statistics to analyze the data. Pearson's coefficient was used to examine the association between variables by SPSS19.

\section{Results}

Demographic characteristics of study samples are shown in Table 1. Mean (SD) age of samples was 16.48 (2.17) years. Mean, standard deviation, minimum and maximum scores of the research variables are shown in Table 2.

Table 3 presents the results of Pearson correlation coefficient test between the addiction potential variable and Islamic lifestyle components. The findings presented in Table 3 show an inverse significant relationship between Islamic lifestyle and addiction potential at a $\mathrm{P}$ value $<0.01$; those who have adopted an Islamic lifestyle exhibit lower addiction potential. According to the table, all subscales of Islamic lifestyle exhibit this association, apart from timeliness (0.08). The more the Islamic lifestyle is adopted, the lower the addiction potential among adolescents.

\section{Discussion}

This study was conducted to examine the association between Islamic lifestyle and addiction potential among students. The results showed that there was an inverse significant association between each component of Islamic lifestyle (except for timeliness) and addiction potential. In other words, those who adopt an Islamic lifestyle are less inclined to use substances. This finding is similar to those of Piko and Fitzpatrick, that showed religious beliefs deterrent effect on drug use (Piko \& Fitzpatrick, 2004), Also is similar to Johnson, Sheets,

Table 1. Demographic characteristics of study samples

\begin{tabular}{|c|c|c|c|}
\hline \multicolumn{2}{|c|}{ Variable } & No. & $\%$ \\
\hline \multirow[b]{2}{*}{ Sex } & Girl & 107 & $50.7 \%$ \\
\hline & Boy & 104 & $49.3 \%$ \\
\hline \multirow{3}{*}{ Grade in high school } & First grade & 65 & $30.8 \%$ \\
\hline & Second grade & 71 & $33.65 \%$ \\
\hline & Third grade & 75 & $35.55 \%$ \\
\hline
\end{tabular}

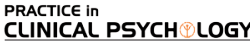

Table 2. Mean, standard deviation, minimum and maximum scores of the research variables

\begin{tabular}{cccccc}
\hline Variables & Mean & SD & No. & Min Score & Max Score \\
\hline Islamic lifestyle & 550 & 60 & 211 & 351 & 711 \\
Addiction potential & 39 & 15 & 211 & 14 & 88 \\
\hline & & & & $\begin{array}{l}\text { PRACTICE in } \\
\text { CLINICAL PSYCH LOGY }\end{array}$
\end{tabular}


Table 3. Pearson correlation coefficient test; the association between Islamic lifestyle components and addiction potential

\begin{tabular}{ccccccccc}
\hline $\begin{array}{c}\text { Statistical } \\
\text { Indices }\end{array}$ & $\begin{array}{c}\text { Overal } \\
\text { Lifestyle }\end{array}$ & Beliefs & Ethical & Health & Social & Familial & Contemplation & Timeliness \\
\hline $\begin{array}{c}\text { Correlation } \\
\text { coefficient }\end{array}$ & -0.45 & -0.43 & -0.39 & -0.35 & -0.35 & -0.29 & -0.21 & -0.12 \\
P-value & 0.01 & 0.01 & 0.01 & 0.01 & 0.01 & 0.01 & 0.01 & 0.08 \\
\hline
\end{tabular}

and Kristeller findings that showed deterrent effect of religious beliefs on alcohol use (Johnson et al., 2008).

For more explanation, a religious person, who follows the Islamic way or pious way of life, adheres to the sacred commandments, and his behavior and actions do not hurt himself, his family, or the society. Also, Miri and Bahrami-Ehsan have shown the influence of religiosity in discouraging drug use among students (Miri \& Bahrami, 2001). If we were to explain our finding, we could say that Islam focuses on all human aspects; people have duties toward themselves, their families and community and addiction is treated as an affliction that harms the individual, family, and community.

A muslim who adopts an Islamic lifestyle is one who abides by Islam's rules, whose actions and behavior do not harm one self, family, or community. Islam values family a great deal. A person who abides by Islamic rules will avoid actions and behaviors such as addiction that will harm his family (Kaviani, 2011). Therefore, it seems that the greater one adopts an Islamic lifestyle, the less one is predisposed to addiction. Our results approve the aforementioned statements. On the other hand, research shows that after high-risk teenage years, the risk of addiction greatly decreases (Eisen, Zellman, \& Murray, 2003), Therefore, the results of this study can be considered in the planning of preventive measures.

Study limitations: The current study has only examined Eslamshahr high-school students; hence we face limitations in generalizing the findings to other academic levels and locations. Accuracy of responses due to respondent bias should be considered as an important limitation for the Islamic lifestyle questionnaire because of religious values in Iran and questionnaire is a self-report tool. Further studies are suggested in this regard.

Those adopting an Islamic lifestyle are less prone to substance abuse. The results of this study demonstrate the inhibitory effect of Islamic lifestyle on the propensity to addiction and highlight the importance of prevention and education from an early age. We live in an Islamic country and Islam is one of the divine religions practiced by people. Thus, we recommend conducting further studies on Islamic lifestyle and its association with other psychological harms. Moreover, studies on the determinant factors of adolescents' psychological and physical health are warranted.

\section{Acknowledgments}

The paper had no financial supporters. We thank all students who participated in this research.

\section{Conflict of Interest}

The authors declared no conflict of interests.

\section{References}

Baghiani Moghadam M. H., Fazel Poor Sh., Rahai Z. (2008). [A comparison of addicts and non-addicts viewpoint on causes of tendency to addiction (Persian)]. Toloo-e Behdasht, 7(3-4), 40-48.

Bashirian S., Heidarnia A., Allahverdipour H., Hajizadeh E. (2013). [The relationship between self-control and intention to substance abuse in adolescents (Persian)]. Scientific Journal of Hamadan Nursing \& Midwifery Faculty, 20(1), 45-53.

Botvin, G. J. (2000). Preventing drug abuse in schools. Addictive Behaviors, 25(6), 887-897. doi: 10.1016/s0306-4603(00)00119-2

Cazenave, N., \& Michel, G. (2008). Risk-taking behaviour and self-esteem regulations among adolescents: The Parkour. Annals Medico Psychologiques, 166(10), 875-881. doi: 10.1016/j. amp.2008.10.026

Compton, W. M., Thomas, Y. F., Stinson, F. S., \& Grant, B. F. (2007). Prevalence, correlates, disability, and comorbidity of DSM-IV drug abuse and dependence in the United States. Archives of General Psychiatry, 64(5), 566-76. doi: 10.1001/ archpsyc.64.5.566

Dreikurs, R. (1991). The challenge of parenthood. Greenwich: Plume Pub. 
Eisen, M., Zellman, G. L., \& Murray, D. M. (2003). Evaluating the Lions-Quest "skills for adolescence" drug education program. Addictive Behaviors, 28(5), 883-897. doi: 10.1016/s03064603(01)00292-1

Farhoudian, A., Sahimi Izadian, E., Rad Goodarzi, R., Sharifi, V., Mohammadi, M. R., Nejatisafa, A. A. et al. (2006). Iran's contribution to child and adolescent mental health research (1973-2002): A Scientometric Analysis. Iranian Journal of Psychiatry, 1(3), 93-97.

Hall, G. S. (1916). Adolescence: Its psychology and its relations to physiology, anthropology, sociology, sex, crime, religion and education (Vol. 2). New York: D. Appleton and Company

Henderson Jr, R. J. (1991). Addiction as disability: The protection of alcoholics and drug addicts under the Americans with Disabilities Act of 1990. Nashville, Tennessee: Vanderbilt University.

Johnson, T. J., Sheets, V. L., \& Kristeller, J. L. (2008). Identifying mediators of the relationship between religiousness/spirituality and alcohol use. Journal of Studies on Alcohol and Drugs, 69(1), 160-170. doi: 10.15288/jsad.2008.69.160

Kaviani, M. (2011). [Quantification and measurement of Islamic life style (Persian)]. Ravanshenasi Va Din, 4(2), 27-44.

Kaviani, M. (2013). [Islamic life style and it's measuring tool $\left(1^{\text {st }} \mathrm{ed}\right.$.) (Persian)]. Qom: Howzeh va Daneshgah.

Massah, O., HoseinSabet, F., Doostian, Y., A'zami, Y., \& Farhoudian, A. (2014). The role of sensation-seeking and coping strategies in predicting addiction potential among students. Practice in Clinical Psychology, 2(3), 200-206.

Matud, M. P., Camacho, J., Hernandez, J. A., Marrero, R. J., Carballeira, M., Lopez, M., \& Rodriguez, C. (2004). Stress and Health in Spanish Women1. Journal of Applied Social Psychology, 34(4), 731-746. doi: 10.1111/j.1559-1816.2004.tb02567.x

Miri, M., \& Bahrami, H. (2001). [The association between religiosity and demographic factors with drug abuse among students (Persian)]. Ravanshenasi Va Din, 3(4), 109-126.

Narenjiha, H., Rafiei, H., Baghestani, A., Noori, R., Ghafouri, B., Soleymaninia, L., et al. (2009). [Rapid situation assessment of substance abuse and dependency in Islamic republic of Iran ( $1^{\text {st }} \mathrm{ed}$.) (Persian)]. Tehran: Danjeh.

Pederson, L. L., \& Stavraky, K. L. (1987). Relationship of Smoking to Lifestyle Factors in Women. Women $\mathcal{E}$ Health, 12(2), 47-66. doi: 10.1300/j013v12n02_04

Piko, B. F., \& Fitzpatrick, K. M. (2004). Substance use, religiosity, and other protective factors among Hungarian adolescents. Addictive Behaviors, 29(6), 1095-1107. doi: 10.1016/j.addbeh.2004.03.022

Sahebzamani, M., Fesharaki, M., \& Abdollahi Mofrad, Z. (2010). [Association of life style and self-esteem among adolescent girls of daily public high schools of Tehran (Persian)]. Medical Sciences, 20(1), 45-51.

Sarrami, H., Ghorbani, M., \& Minooei, M. (2013). [Survey of four decades of addiction prevalence researches in Iran (Persian)]. Research on Addiction, 7(26), 29-52.

Suwazono, Y. (2003). A follow-up study on the association of working conditions and lifestyles with the development of (perceived) mental symptoms in workers of a telecommunication enterprise. Occupational Medicine, 53(7), 436-442. doi: 10.1093/occmed/kqg102
Suzuki, K., Kitaike, T., Miyazaki, Y., \& Nojiri, M. (2003). Factors related to the mental health of workers dispatched to foreign countries. Journal of occupational health, 45(3), 105-113. doi: 10.1539 /sangyoeisei.45.105

Visser, J. H., Van der Ende, J., Koot, H. M., \& Verhulst, F. C. (2000). Predictors of psychopathology in young adults referred to mental health services in childhood or adolescence. The British Journal of Psychiatry, 177(1), 59-65. doi: 10.1192/ bjp.177.1.59

Weed, N. C., Butcher, J. N., McKenna, T., \& Ben-Porath, Y. S. (1992). New measures for assessing alcohol and drug abuse with the MMPI-2: The APS and AAS. Journal of Personality Assessment, 58(2), 389-404. doi: 10.1207/s15327752jpa5802_15

Yang, C. K., Choe, B. M., Baity, M., Lee, J. H., \& Cho, J. S. (2005). SCL-90-R and 16PF profiles of senior high school students with excessive internet use. The Canadian Journal of Psychiatry, 50(7), 407-414. doi: 10.1177/070674370505000704

Yousefi-Nooraie, R., Farhoudian, A., Amini, H., Mohammadi, M. R., Mesgarpour, B., Mansouri, N., et al. (2009). Prevalence of mental disorders among high-school students in Iran: A systematic review. Iranian Journal of Psychiatry, 4(1), 1-6.

Zargar, A., Najarian, B., \& Naami, A. (2008). [The relationship between personality traits (sensation seeking, assertiveness, psychological hardiness), religion attitudes and marital satisfaction with readiness for drug abuse (Persian)]. Journal of Studies in Education and Psychology, 1(3), 99-120.

Zimmerman, M. A., \& Maton, K. I. (1992). Life-style and substance use among male African American urban adolescents: A cluster analytic approach. American Journal of Community Psychology, 20(1), 121-138. doi: 10.1007/bf0094218 


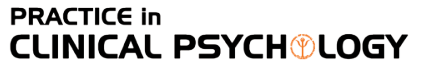

January 2017, Volume 5, Number 1

32

Padarvand, A., et al. (2017). The Association Between Islamic Lifestyle and Addiction Potential Among Adolescents. JPCP; 5(1), 27-32. 